\title{
Inspiration for the Future: The Role of Inspiratory Muscle Training in Cystic Fibrosis
}

\author{
Ren-Jay Shei ${ }^{1,2^{*}} \mathbb{D}$, Robert L. Dekerlegand ${ }^{3} \mathbb{D}$, Kelly A. Mackintosh ${ }^{4} \mathbb{D}$, John D. Lowman ${ }^{2,5} \mathbb{D}$ and Melitta A. McNarry ${ }^{4} \mathbb{D}$
}

\begin{abstract}
Cystic fibrosis (CF) is an inherited, multi-system, life-limiting disease characterized by a progressive decline in lung function, which accounts for the majority of CF-related morbidity and mortality. Inspiratory muscle training (IMT) has been proposed as a rehabilitative strategy to treat respiratory impairments associated with CF. However, despite evidence of therapeutic benefits in healthy and other clinical populations, the routine application of IMT in CF can neither be supported nor refuted due to the paucity of methodologically rigorous research. Specifically, the interpretation of available studies regarding the efficacy of IMT in CF is hampered by methodological threats to internal and external validity. As such, it is important to highlight the inherent risk of bias that differences in patient characteristics, IMT protocols, and outcome measurements present when synthesizing this literature prior to making final clinical judgments. Future studies are required to identify the characteristics of individuals who may respond to IMT and determine whether the controlled application of IMT can elicit meaningful improvements in physiological and patient-centered clinical outcomes. Given the equivocal evidence regarding its efficacy, IMT should be utilized on a case-by-case basis with sound clinical reasoning, rather than simply dismissed, until a rigorous evidence-based consensus has been reached.
\end{abstract}

\section{Key Points}

- Preliminary evidence indicates that inspiratory muscle training could enhance respiratory muscle function in CF, although whether this translates to meaningful physiological and patient-centered improvements is unclear.

- The poor quality of evidence limits the conclusions that can be drawn and highlights the need for future studies that utilize appropriate measures and training protocols and characterize the patient population to enable conclusions to be drawn regarding the potential therapeutic benefits of IMT in CF.

\footnotetext{
* Correspondence: rshei@uab.edu

${ }^{1}$ Division of Pulmonary, Allergy, and Critical Care Medicine, Department of Medicine, University of Alabama at Birmingham, 1918 University Boulevard, Birmingham, AL 35294-0006, USA

${ }^{2}$ Gregory Fleming James Cystic Fibrosis Research Center, University of

Alabama at Birmingham, Birmingham, AL, USA

Full list of author information is available at the end of the article
}

- Until such studies have been conducted, conclusions on the value of IMT as a treatment tool in CF cannot be drawn and as such, IMT should be considered on a case-by-case basis.

\section{Introduction}

Cystic fibrosis (CF) is an autosomal recessive genetic disorder caused by mutations in the cystic fibrosis transmembrane conductance regulator (CFTR) gene that results in multi-organ pathologies involving the respiratory, digestive, and reproductive systems [1-3]. Specific to the respiratory system, aberrant or absent CFTR channels produce a dehydrated, hyper-viscous, and acidic mucosal layer that promotes an airway environment prone to chronic infection and inflammation that leads to progressive lung injury. Airway obstruction becomes evident in pulmonary function tests as does a progressive lung hyperinflation associated with a reduction in forced expiratory volume in $1 \mathrm{~s}\left(\mathrm{FEV}_{1}\right)[4,5]$. The resultant increased work of breathing (WOB) and decreased gas exchange contribute to impaired exercise 
capacity and ultimately respiratory failure, which is the leading cause of CF-related mortality $[1,2]$.

Alterations in pulmonary mechanics associated with progressive CF pathophysiology include the adoption of a rapid, shallow breathing pattern [6], which may delay respiratory muscle fatigue [7], but also contribute to increased WOB and impaired gas exchange $[6,8]$. Multiple CF-related comorbidities, including thoracic kyphosis and postural abnormalities, can create a restrictive lung dysfunction that elevates the demand imposed on the respiratory pump $[9,10]$. Thus, individuals with CF commonly exhibit an imbalance between the ventilatory load and the capacity of the respiratory muscles, which is exemplified by the adoption of inefficient breathing patterns [6] and exercise intolerance [11].

Although alterations in pulmonary mechanics and WOB in individuals with CF are clear, it is equivocal whether individuals with CF exhibit respiratory (inspiratory and/or expiratory) muscle dysfunction or preserved respiratory muscle function $[12,13]$. It is evident, however, that respiratory muscle function is influenced by a variety of factors including hyperinflation, nutritional status [14], systemic corticosteroid use, Pseudomonas aeruginosa colonization, inactivity, and chronic inflammation [15]. Importantly, respiratory muscle performance in CF is a key determinant of aerobic fitness [15], which is closely associated with survival [16] and quality of life (QoL) [17-19]. Thus, addressing whether inspiratory and expiratory muscle function is preserved or aberrant in CF will be important to identify novel methods to optimize respiratory pump function in CF, including inspiratory muscle training (IMT).

Strategies to enhance respiratory muscle function in the presence of a load/capacity imbalance and to counteract the disease-related decline in pulmonary function have been suggested, with one potential strategy being IMT [20, 21]. While specific loading protocols vary, IMT typically utilizes either a pressure or volume load on the inspiratory muscles to provide a stimulus to elicit a training response [22], similar to that observed in response to training peripheral musculature. Indeed, IMT has been shown to be an effective ergogenic aid to enhance exercise performance in healthy adults [23-26] and has been investigated as a therapeutic intervention to improve clinical and functional outcomes in a variety of health conditions including asthma, chronic obstructive pulmonary disease (COPD), heart failure, and stroke [27-33]. However, the applicability of IMT as a therapeutic strategy in those with CF remains equivocal [20]. Nonetheless, whilst recent reviews have provided a comprehensive summary of the current evidence base, little attention has been given to the methodological limitations associated with this evidence, which largely confounds its interpretation and should temper any conclusions. Therefore, the purpose of the present opinion paper is to draw attention to past and ongoing challenges with IMT studies and to provide recommendations on how future studies may seek to address such shortcomings to provide a better understanding of how IMT may, or may not, fit into the armamentarium of tools to manage CF.

\section{Current State of IMT in CF}

A summary of peer-reviewed publications on IMT in individuals with CF is given in Table 1. Despite the rehabilitative and therapeutic potential of IMT, its clinical efficacy and long-term application in CF remains inconclusive as no study to date has provided strong evidence of significant improvements in clinical outcomes, regardless of improvements in inspiratory muscle performance. It should be noted, however, that IMT has been associated with improved exercise tolerance [34] and improved health-related QoL within the mastery and emotion domains $[34,35]$. The apparent limited utility of IMT to translate to clinically meaningful outcomes must be interpreted in the context of multiple methodological limitations and the obvious paucity of available studies. Indeed, the most recent Cochrane review only identified nine reports eligible for inclusion [20]. Whilst the overall conclusion of this review appears to be appropriate based on the available evidence, several parameters that may underpin the equivocal findings were not adequately discussed, such as the methods utilized to quantify respiratory muscle function [36]. Furthermore, little distinction was made between children and adults within this recent review, despite significant physiologic and psychosocial age-related differences that may impact the plasticity and response to IMT. This observation is of particular concern given the inherent interaction between age and disease progression in $\mathrm{CF}$, which is highly likely to influence the efficacy of any intervention. The lack of available data limits child-adult comparisons, and although Hilton et al. [20] proposed an arbitrary 16year-old cut-point to distinguish adults, this threshold may be inappropriate given the delayed biological maturation that may occur with $\mathrm{CF}[37,38]$.

The conflicting and uncertain results on the efficacy of IMT in CF may also be partially explained by variations in training protocols between studies [21]. Indeed, the contention that flow-based and threshold modes of IMT provide a similar training stimulus to the muscles, as cited in the recent Cochrane review [20], is controversial. Specifically, threshold devices do not provide a constant challenge throughout the inspiratory effort, while flow-based training is dependent on flow rates and breathing pattern [39]. In accord with skeletal muscle adaptations to training, it is vital to identify the optimal training protocol prior to conclusions being drawn 
Table 1 Summary matrix of original published studies investigating inspiratory muscle training in individuals with cystic fibrosis

\begin{tabular}{|c|c|c|c|c|}
\hline Study & $\begin{array}{l}\text { Patient } \\
\text { demographics* }\end{array}$ & Protocol & Comparison & Primary outcomes \\
\hline $\begin{array}{l}\text { Asher, } \\
1982\end{array}$ & $\begin{array}{l}\text { Age: } 16.0 \pm 4.6 \\
\% \mathrm{BMI}: 82.6 \pm 9.9 \\
\% \mathrm{FEV}_{1}: 35.0 \pm \\
12.3 \\
\text { MIP: } 74 \pm 18\end{array}$ & $\begin{array}{l}\text { Mode: Flow-based } \\
\text { Intensity: } R_{\max } \\
\text { Frequency: BID } \\
\text { Duration: } 15 \mathrm{~min} / \text { day; } 4 \text { weeks }\end{array}$ & $\begin{array}{l}\text { Subjects served as their own } \\
\text { controls with a 4-week control } \\
\text { period followed by a 4-week } \\
\text { intervention period. }\end{array}$ & $\begin{array}{l}\text { Increase in IMS }(9.5 \% ; p<0.025) \text { and IME; } \\
\text { no effect on exercise performance. }\end{array}$ \\
\hline $\begin{array}{l}\text { Sawyer, } \\
1993\end{array}$ & $\begin{array}{l}\text { Age: } 11.5 \pm 2.5 \\
\text { BMI**: } 18.4 \\
\text { NIHS: } 87.7 \\
\text { MIP: } 107 \pm 29\end{array}$ & $\begin{array}{l}\text { Mode: Threshold } \\
\text { Intensity: } 50-60 \% \text { MIP } \\
\text { Frequency: } 7 \text { days/week } \\
\text { Duration: } 30 \text { min/day; } 10 \text { weeks }\end{array}$ & $\begin{array}{l}\text { Compared to a sham group } \\
\text { who performed trained at } \\
\leq 10 \% \text { MIP. }\end{array}$ & $\begin{array}{l}\text { Increase in MIP }(13 \% ; p<0.01) \text {, VC }(17 \%) \text {, } \\
\text { TLC }(13 \% ; p<0.01) \text {, and maximal exercise } \\
\text { capacity }(9.8 \% ; p<0.03) \text { with observed } \\
\text { increase in sputum production. }\end{array}$ \\
\hline $\begin{array}{l}\text { De Jong, } \\
2001\end{array}$ & 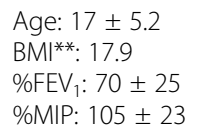 & $\begin{array}{l}\text { Mode: Threshold } \\
\text { Intensity: } 40 \% \text { MIP } \\
\text { Frequency: } 5 \text { days/week } \\
\text { Duration: } 20 \text { min; } 6 \text { weeks }\end{array}$ & $\begin{array}{l}\text { Compared to a sham group } \\
\text { who performed trained at } \\
10 \% \text { MIP. }\end{array}$ & $\begin{array}{l}\text { Increase in IME (35\%; } p=0.003) \text { with no } \\
\text { significant effect on exercise, dyspnea, } \\
\text { or fatigue. }\end{array}$ \\
\hline $\begin{array}{l}\text { Enright, } \\
2004\end{array}$ & $\begin{array}{l}\text { Age: } 24.8 \pm 5.5 \\
\text { BMI**: } 22.3^{* F_{E V V}: 64.2 \pm} \\
29.7 \\
\text { MIP: } 134 \pm 26\end{array}$ & $\begin{array}{l}\text { Mode: Computer interface } \\
\text { Intensity: } 80 \% \text { SMIP } \\
\text { Frequency: } 3 \text { days/week } \\
\text { Duration: } 6 \text { sets, } 6 \text { reps; } 8 \text { weeks }\end{array}$ & $\begin{array}{l}\text { Compared to a sham group } \\
\text { at } 20 \% \text { SMIP and a control group. }\end{array}$ & $\begin{array}{l}\text { Increased SMIP and MIP with } 80 \% \text { and } \\
20 \% \text { training groups with no between } \\
\text { group differences. Increased diaphragmatic } \\
\text { thickness (20\%), VC ( } 24 \%) \text {, TLC (12\%), and } \\
\text { PWC ( } 51 \%) \text {; decreased anxiety and depression } \\
\text { in the } 80 \% \text { group only. }\end{array}$ \\
\hline $\begin{array}{l}\text { Santana- } \\
\text { Sosa, } 2014\end{array}$ & 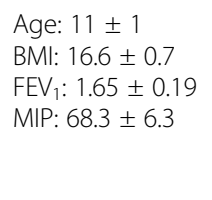 & $\begin{array}{l}\text { Mode: Threshold combined with } \\
\text { exercise program. } \\
\text { Intensity: } 40-50 \% \text { MIP } \\
\text { Frequency: BID } \\
\text { Duration: } ~ 5 \text { min of } 30 \\
\text { inspirations; } 8 \text { weeks }\end{array}$ & $\begin{array}{l}\text { Compared to a sham group } \\
\text { who was trained at } 10 \% \text { MIP. }\end{array}$ & $\begin{array}{l}\text { Increased MIP }(58 \%), \mathrm{VO}_{2} \text { peak }(22 \%) \text {, and } \\
\text { muscular strength in the intervention group. }\end{array}$ \\
\hline Bieli, 2017 & 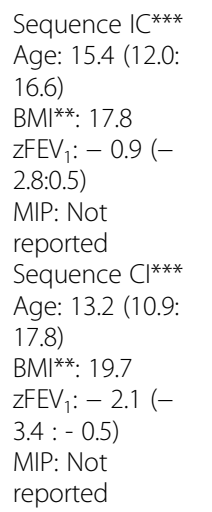 & $\begin{array}{l}\text { Mode: Eucapnic hyperventilation } \\
\text { Intensity: Not reported } \\
\text { Frequency: BID, } 5 \text { days/week } \\
\text { Duration: } 10 \text { min; } 8 \text { weeks }\end{array}$ & $\begin{array}{l}\text { Randomized crossover } \\
\text { comparison. }\end{array}$ & $\begin{array}{l}\text { Increased RME (105\%) but not exercise } \\
\text { endurance, lung function, or quality of life. }\end{array}$ \\
\hline
\end{tabular}

$B I D$ two times per day, $B M I$ body mass index, \%BMI body mass index percentile, $\% F E V_{1}$ percent of predicted forced expiratory volume in $1 \mathrm{~s}, F E V_{1}$ forced expiratory volume in $1 \mathrm{~s}$ expressed as liters per second, $z F E V$ forced expiratory volume in $1 \mathrm{~s}$ expressed a $z$-score, $\% R V$ percent of predicted residual volume, $R_{\text {max }}$ greatest resistance sustainable for $10 \mathrm{~min}, I M S$ inspiratory muscle strength, IME inspiratory muscle endurance, \%MIP percent of predicted maximal inspiratory pressure, MIP maximal inspiratory pressure in $\mathrm{cmH}_{2} \mathrm{O}, N I H S$ National Institutes of Health Score for disease severity, NR not reported, QD daily, $P W C$ physical work capacity, SMIP sustained maximal inspiratory pressure, $T L C$ total lung capacity, $V C$ vital capacity, $V O_{2}$ peak peak rate of oxygen consumption *Patient demographics given for baseline characteristics of the intervention group **Calculated from height and weight provided in the article

***Values presented as median (interquartile range); $C l$ control-intervention sequence, $I C$ intervention-control sequence

regarding the efficacy of any training stimulus. At least in healthy humans, the efficacy of IMT as an ergogenic aid appears to be optimal when the IMT loading protocol is closely matched to the ventilatory demands of the criterion task (i.e., exercise modality) [24, 25], which has not been identified in CF. Indeed, the optimization of IMT is likely to be a highly individualized process requiring the IMT protocol to be matched with specifically identified respiratory muscle impairments. In this manner, an appropriate IMT protocol targeting strength and/or endurance deficits based on the individual's needs may elicit optimal physiological benefits. However, despite their potential impact on intervention efficacy, these considerations have not been rigorously controlled for in prior studies on IMT in CF.

Further to resolving these methodological issues, the potential mechanisms underpinning the ability of IMT to elicit meaningful physiological and psychosocial benefits should be considered. It is possible that the apparent variability in the effect of IMT reflects inter-participant variations in disease manifestation and management that are of significant clinical and functional relevance, 
especially as the drive towards personalized/precision medicine continues $[40,41]$.

\section{Inspiratory Muscle Training: Potential Mechanistic Basis for Adaptations}

The specific mechanisms by which IMT can transfer to meaningful outcomes in individuals with $\mathrm{CF}$ are unclear and likely multifactorial. However, several putative mechanisms have emerged, including (i) hypertrophy of the diaphragm and external intercostal muscles, (ii) an increase in the proportion of type I fibers in the external intercostal muscles, (iii) improvement in respiratory muscle economy and efficiency, (iv) reduction in the work of breathing, (v) enhanced respiratory muscle strength and endurance, (vi) attenuation of the respiratory muscle metaboreflex, (vii) reduction in cytokine release, (viii) reorganization of respiratory muscle motor recruitment pattern, (ix) decreased inspiratory muscle motor drive with preserved inspiratory pressure generation, and (x) decreased rating of perceived breathlessness and/or rating of perceived exertion [24, 42]. These mechanisms are likely interrelated and not mutually exclusive. Their interaction, and ultimately their impact on exercise performance, is not well understood. Whilst these potential mechanisms have been identified in healthy populations and their applicability to clinical populations, such as CF, remains to be elucidated, there are no grounds to postulate that the mechanisms may differ, although the emphasis on each factor may be disease-specific. For example, a reduction in cytokine release may be especially beneficial in a disease characterized by systemic inflammation, further highlighting the potential utility of IMT if shown to be effective.

\section{Expert Opinion on IMT in CF}

Although IMT has the potential to be a useful rehabilitative and therapeutic tool for the management of CF lung disease, several crucial weaknesses in the current body of literature must be addressed in order to clarify its degree of utility. The grading of the evidence for IMT in $\mathrm{CF}$ as "very low quality" in the most recent Cochrane systematic review [20] highlights the challenges of conducting IMT studies in those with CF. The heterogeneity between and within studies, including wide variations in methodologies and outcome measures, the incomplete reporting of important parameters such as clinical status, and in the methods of randomization, allocation, and blinding [20], preclude firm conclusions to support or refute the use of IMT in this population. Indeed, methodologically rigorous studies that accurately and completely report these factors are required to come to a valid, evidence-based, consensus regarding the therapeutic efficacy of IMT in individuals with CF. The primary challenges within studies of IMT in those with
$\mathrm{CF}$ that need to be addressed include (i) adequate consideration and controlling of the characteristics of the patient population, (ii) carefully targeting the IMT protocol based on individual needs, and (iii) selecting outcome measures that best capture both physiological adaptations and patient-centered clinical outcomes.

Careful consideration of the patient population will be required, with future studies encouraged to control for contextual factors including, but not limited to, age, disease severity, baseline respiratory muscle performance, bacterial colonization status, modulator therapy status, aerobic fitness, body composition, rate of pulmonary function deterioration, and mutation class. Figure 1 presents the International Classification of Functioning, Disability, and Health framework on components ultimately affecting QoL in CF. Research is needed to identify which of these components are most influential in mediating and/or moderating the response to IMT, and controlling for these components should be a priority in future studies. Specific to IMT, in addition to respiratory muscle function or dysfunction (including both inspiratory and expiratory muscles), core stability and pelvic floor function may also impact the response to IMT. At present, there is a dearth of published data describing whether these factors are abnormal in CF; nevertheless, these factors may still influence respiratory muscle performance and should therefore be accounted for in future studies of IMT in CF. Additionally, IMT may also improve both core stability and pelvic floor function suggesting these may be important outcome factors to include in future studies as well. In the meantime, the use of strict inclusion and exclusion eligibility criteria will ensure a more homogeneous sample population and thereby address at least some of these components. In addition, the development of a standardized method of assessing, and subsequently grading, disease status and severity according to phenotypic determinants of respiratory muscle impairments would facilitate a more targeted, personalized approach to IMT, acknowledging that IMT may not benefit all with $\mathrm{CF}$ to the same degree.

Identifying the most suitable IMT protocol presents another significant challenge for IMT studies, with further research warranted to distinguish the most salient merits associated with the different types of resistive loading, including pressure-threshold and flow-resistive loading, as well as volume loading (i.e., voluntary hyperpnea) [27]. Importantly, the optimal training volume and intensity for IMT protocols must be elucidated; we must seek to move away from the reliance on a "one-size-fitsall" approach. Indeed, due to the phenotypic heterogeneity in those with CF, innovative IMT programs that provide a sufficient training dose to elicit specific physiological adaptations in the respiratory muscles need to be developed. For example, a patient who exhibits 


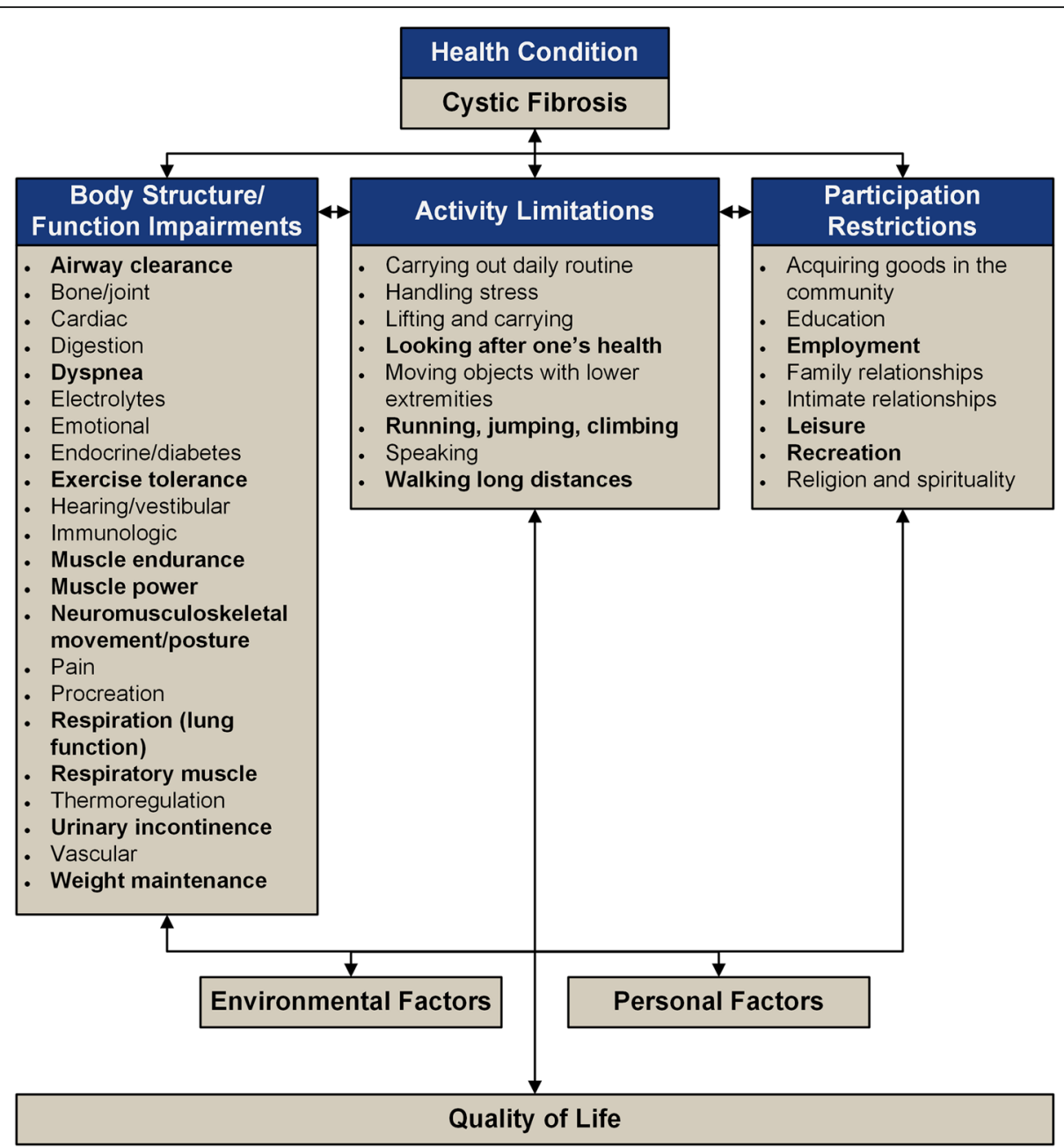

Fig. 1 The International Classification of Functioning, Disability and Health (ICF) framework describing the interrelated body structure/function impairments, activity limitations, and participation restrictions that can occur in cystic fibrosis, limitations, and restrictions as a result of CF, and highlights (in bold) those that, in particular, are related to inspiratory muscle function. Adapted from [43]

significant respiratory muscle weakness but preserved respiratory muscle endurance should receive a markedly different training protocol compared to a patient with preserved respiratory muscle strength but diminished respiratory muscle endurance. Furthermore, it is likely that some of those with CF, particularly those who experience a pseudo-training effect as a result of chronic airway obstruction, may require a higher training workload compared with healthier counterparts. Indeed, analogous findings have been reported in healthy elite swimmers in whom the habitual exposure to an increased WOB, due to the hydrostatic pressure the water exerts on the thorax, ameliorates the potential benefits typically engendered by IMT [44], an effect not found with lower exposures to this increased WOB $[45,46]$. Alternatively, some individuals with CF may simply not benefit from IMT. For example, it is possible that particularly in the presence of mild disease and preserved respiratory muscle function, IMT may not be of any additional benefit to the current standard of care. The ergogenic effect of strength training on limb locomotor muscles appears to be optimized when athletes perform strength training to task failure [47-49]. Therefore, the development of CF-specific IMT protocols that progress to task failure (e.g., failure to generate a given inspiratory pressure during IMT) may provide the greatest potential therapeutic benefit of IMT in those with CF [50]. IMT performed at $100 \%$ of $P_{\text {Imax }}$ has been shown to decrease exercising heart rate and perceived exertion, whereas IMT performed at $80 \%$ of $P_{\operatorname{Imax}}$ did not produce any such adaptations [51]. Presently, the test of incremental respiratory endurance (TIRE) regimen, which consists of a series of training breaths with a decreasing work-rest ratio, may be the best example of such an IMT protocol [22, 24, 27, 52-54]. Specifically, this type of training prescription may be better suited to inducing respiratory 
muscle adaptations in those with CF compared with protocols simply requiring a fixed number of breaths in each training session. Similarly, adopting a "high-intensity interval training" (HIIT)-like prescription of IMT may also enhance the potential efficacy and sustainability of this training modality, as HIIT has been shown to be effective in inducing similar training adaptations to those observed following whole-body exercise training in a more time-efficient manner.

Most IMT studies report pulmonary function-related outcome measures such as $\mathrm{FEV}_{1}$ and $\mathrm{FVC}$, as well as some respiratory muscle performance parameters such as maximal inspiratory and expiratory mouth pressures ( $P_{\text {Imax }}$ and $P_{\text {Emax }}$, respectively), to gauge respiratory muscle strength. However, these measures alone may not be sufficient to evaluate the efficacy of IMT on enhancing respiratory muscle performance [52]. Employing additional outcome measures to detect physiological adaptations, such as diaphragm and external intercostal muscle hypertrophy and motor unit recruitment pattern changes, will be informative as to whether IMT is effective in inducing true training adaptations. However, it is important to be cognizant that many such measures are not in routine clinical use and are therefore likely to be unfamiliar to people with CF and their interdisciplinary care teams. Consequently, these data may not be useful for many practitioners as they are unable to draw meaningful conclusions. Thus, these additional measures should be considered in conjunction with functional and clinical measures, such as respiratory muscle economy, ventilatory efficiency, breathing patterns, dyspnea, QoL, and participant burden.

Finally, and of utmost importance, is not whether IMT can improve respiratory muscle performance per se, but whether these improvements can transfer to more meaningful, patient-centered clinical outcomes such as those from maximal cardiopulmonary exercise testing (e.g., aerobic capacity, peak ventilation, ventilatory threshold, ventilatory efficiency) [55], health-related QoL, morbidity, health-care utilization, and even mortality. This interdisciplinary, holistic approach will allow for a more complete understanding of the physiological adaptations and subsequent clinical outcomes that can result from IMT in those with CF. This is particularly important given that those with CF already face a high burden of care [56]. Therefore, identifying whether IMT provides additive or unique benefits distinct from exercise training alone will aid in establishing whether IMT has value in the standard of care for individuals with CF.

\section{Conclusion}

The potential for IMT to be a useful therapeutic tool in $\mathrm{CF}$ care remains equivocal. The present lack of quality empirical evidence supporting or refuting the use of
IMT in CF highlights the challenges of designing and conducting IMT studies in CF. Future research should seek to address these challenges. Specifically, more thorough and complete reporting of important demographic information, including considerations of pertinent clinical outcome data, as well as an assessment of targeted training effects of IMT should provide a more comprehensive understanding of its efficacy in those with CF. Similarly, developing a standardized method for assessing and quantifying respiratory muscle (dys) function in order to individualize IMT training programs in CF is of utmost importance. Finally, future research should consider whether the potential benefits of IMT outweigh the additional burden placed in those living with CF.

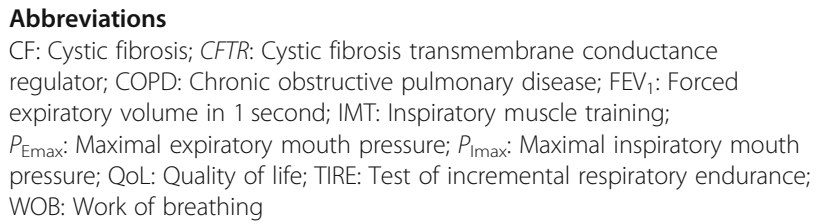

$\mathrm{RS}, \mathrm{RD}, \mathrm{KM}, \mathrm{J}$, and MM all contributed to the manuscript conception, preparation, and final editing. All authors approved the final manuscript before submission.

\section{Funding}

This work was supported by the National Institutes of Health/National Heart, Lung, and Blood Institute [Ren-Jay Shei: T32HL105346] and the Cystic Fibrosis Foundation [John D. Lowman: CCPT250-16]. The funders had no role in the design, interpretation, or writing of the manuscript.

Availability of Data and Materials

Data sharing is not applicable to this article as no datasets were generated or analyzed during the current study.

Ethics Approval and Consent to Participate Not applicable.

Consent for Publication

Not applicable

\section{Competing Interests}

The authors, Ren-Jay Shei, Robert L. Dekerleg, Kelly A. Mackintosh, John D. Lowman, and Melitta A. McNarry, declare that they have no competing interests.

\section{Author details}

${ }^{1}$ Division of Pulmonary, Allergy, and Critical Care Medicine, Department of Medicine, University of Alabama at Birmingham, 1918 University Boulevard, Birmingham, AL 35294-0006, USA. ²Gregory Fleming James Cystic Fibrosis Research Center, University of Alabama at Birmingham, Birmingham, AL, USA. ${ }^{3}$ Department of Physical Therapy, College of Rehabilitation Sciences, Jefferson (Philadelphia University and Thomas Jefferson University), Philadelphia, PA, USA. ${ }^{4}$ Applied Sports Science Technology and Medicine Research Centre (A-STEM), College of Engineering, Swansea University, Swansea, UK. ${ }^{5}$ Department of Physical Therapy, School of Health Professions, University of Alabama at Birmingham, Birmingham, AL, USA. 
Received: 28 March 2019 Accepted: 31 July 2019 Published online: 08 August 2019

\section{References}

1. Ratjen F, Bell SC, Rowe SM, Goss CH, Quittner AL, Bush A. Cystic fibrosis. Nat Rev Dis Primers. 2015;1:15010. https://doi.org/10.1038/nrdp.2015.10.

2. Elborn JS. Cystic fibrosis. Lancet. 2016;388(10059):2519-2531. doi:https://doi org/https://doi.org/10.1016/S0140-6736(16)00576-6

3. Rowe SM, Miller S, Sorscher EJ. Cystic fibrosis. N Eng J Med. 2005;352(19): 1992-2001. https://doi.org/10.1056/NEJMra043184.

4. Grasemann H, Ratjen F. Early lung disease in cystic fibrosis. Lancet Respir Med. 2013;1(2):148-157. doi:https://doi.org/https://doi.org/10.1016/S2213-26 00(13)70026-2

5. Kraemer R, Aebi C, Casaulta Aebischer C, Gallati S. Early detection of lung disease and its association with the nutritional status, genetic background and life events in patients with cystic fibrosis. Respiration. 2000;67(5):477-90.

6. Hart N, Polkey MI, Clément A, Boulé M, Moxham J, Lofaso F, et al. Changes in pulmonary mechanics with increasing disease severity in children and young adults with cystic fibrosis. Am J Respir Crit Care Med. 2002;166(1):616. https://doi.org/10.1164/rccm.2112059.

7. Hahn A, Ankermann T, Claass A, Mann M, Lindemann H, Neubauer BA. Noninvasive tension time index in relation to severity of disease in children with cystic fibrosis. Pediatr Pulmonol. 2008;43(10):973-81. https://doi.org/10.1002/ ppul.20887.

8. Thin AG, Dodd JD, Gallagher CG, Fitzgerald MX, McLoughlin P. Effect of respiratory rate on airway deadspace ventilation during exercise in cystic fibrosis. Respir Med. 2004;98(11):1063-1070. doi:https://doi.org/https://doi. org/10.1016/j.rmed.2004.03.016.

9. Aris RM, Renner JB, Winders AD, et al. Increased rate of fractures and severe kyphosis: sequelae of living into adulthood with cystic fibrosis. Ann Intern Med. 1998;128(3):186-93. https://doi.org/10.7326/0003-4819-128-3-19980201 0-00004.

10. Denton JR, Tietjen R, Gaerlan PF. Thoracic kyphosis in cystic fibrosis. Clin Orthop Relat Res. 1981;155:71-4.

11. Almajed A, Lands LC. The evolution of exercise capacity and its limiting factors in cystic fibrosis. Paediatr Respir Rev. 2012;13(4):195-9. https://doi. org/10.1016/j.prrv.2012.01.001.

12. Dekerlegand RL, Hadjiliadis D, Swisher AK, Parrott JS, Heuer AJ, Myslinski MJ. Inspiratory muscle strength relative to disease severity in adults with stable cystic fibrosis. J Cyst Fibros. 2015;14(5):639-45. https://doi.org/10.1016/j.jcf.2 015.05.003.

13. Heinzmann-Filho JP, Marostica PJ, Donadio MV. Ventilatory muscle strength in cystic fibrosis patients: a literature review. Monaldi Arch Chest Dis = Archivio Monaldi per le malattie del torace. 2012;77(3-4):134-8. https://doi. org/10.4081/monaldi.2012.147.

14. Dekerlegand RL, Hadjiliadis D, Swisher AK, Parrott JS, Heuer AJ, Myslinski MJ. Clinical predictors of inspiratory muscle strength in adults with stable cystic fibrosis: a pilot study. Cardiopulm Phys Ther J. 2017;28(4):136-46. https://doi. org/10.1097/cpt.0000000000000064.

15. Dassios T. Determinants of respiratory pump function in patients with cystic fibrosis. Paediatr Respir Rev. 2015;16(1):75-79. doi:https://doi.org/https://doi. org/10.1016/j.prrv.2014.01.001.

16. Vendrusculo FM, Heinzmann-Filho JP, da Silva JS, Perez Ruiz M, Donadio MVF. Peak oxygen uptake and mortality in cystic fibrosis: systematic review and meta-analysis. Respir Care. 2018.

17. Hebestreit H, Schmid K, Kieser S, Junge S, Ballmann M, Roth K, et al. Quality of life is associated with physical activity and fitness in cystic fibrosis. BMC Pulm Med. 2014;14(1):26. https://doi.org/10.1186/1471-2466-14-26.

18. Albinni S, Rath R, Renner S, Eichler I. Additional inspiratory muscle training intensifies the beneficial effects of cycle ergometer training in patients with cystic fibrosis. J Cyst Fibros. 2004;3(11S):S63.

19. Moorcroft AJ, Dodd ME, Morris J, Webb AK. Symptoms, lactate and exercise limitation at peak cycle ergometry in adults with cystic fibrosis. Eur Resp J. 2005;25(6):1050-6. https://doi.org/10.1183/09031936.05.00011404.

20. Hilton N, Solis-Moya A. Respiratory muscle training for cystic fibrosis. Cochrane Database Syst Rev. 2018;5:CD006112. https://doi.org/10.1 002/14651858.CD006112.pub4.

21. Reid WD, Geddes EL, O'Brien K, Brooks D, Crowe J. Effects of inspiratory muscle training in cystic fibrosis: a systematic review. Clin Rehabil. 2008; 22(10-11):1003-13. https://doi.org/10.1177/0269215508090619.
22. Enright $\mathrm{S}$, Chatham $\mathrm{K}$, lonescu AA, Unnithan VB, Shale DJ. Inspiratory muscle training improves lung function and exercise capacity in adults with cystic fibrosis. Chest. 126(2):405-11. https://doi.org/10.1378/chest.126.2.405.

23. Karsten M, Ribeiro GS, Esquivel MS, Matte DL. The effects of inspiratory muscle training with linear workload devices on the sports performance and cardiopulmonary function of athletes: a systematic review and metaanalysis. Phys Ther Sport. 2018;34:92-104. doi:https://doi.org/https://doi.org/1 0.1016/j.ptsp.2018.09.004

24. Shei R-J. Recent advancements in our understanding of the ergogenic effect of respiratory muscle training in healthy humans: a systematic review. J Strength Cond Res. 2018;32(9):2665-76. https://doi.org/10.1519/jsc. 0000000000002730.

25. HajGhanbari B, Yamabayashi C, Buna TR, Coelho JD, Freedman KD, Morton $T A$, et al. Effects of respiratory muscle training on performance in athletes: a systematic review with meta-analyses. J Strength Cond Res. 2013;27(6): 1643-63. https://doi.org/10.1519/JSC.0b013e318269f73f.

26. Illi SK, Held U, Frank I, Spengler CM. Effect of respiratory muscle training on exercise performance in healthy individuals. Sports Med. 2012;42(8):707-24. https://doi.org/10.1007/BF03262290.

27. Shei R-J, Paris HLR, Wilhite DP, Chapman RF, Mickleborough TD. The role of inspiratory muscle training in the management of asthma and exerciseinduced bronchoconstriction. Phys Sportsmed. 2016;44(4):327-34. https:// doi.org/10.1080/00913847.2016.1176546.

28. Menezes KKP, Nascimento LR, Ada L, Polese JC, Avelino PR, Teixeira-Salmela LF. Respiratory muscle training increases respiratory muscle strength and reduces respiratory complications after stroke: a systematic review. J Physiother. 2016;62(3):138-144. doi:https://doi.org/https://doi.org/10.1016/j. jphys.2016.05.014.

29. Cahalin LP, Arena RA. Breathing exercises and inspiratory muscle training in heart failure. Heart Failure Clin. 2015;11(1):149-72. https://doi.org/10.1016/j. hfc.2014.09.002.

30. Smart NA, Giallauria F, Dieberg G. Efficacy of inspiratory muscle training in chronic heart failure patients: a systematic review and meta-analysis. Int J Cardiol. 2013;167(4):1502-1507. doi:https://doi.org/https://doi.org/10.1016/j. ijcard.2012.04.029.

31. Charususin N, Gosselink R, Decramer M, Demeyer H, McConnell A, Saey D, et al. Randomised controlled trial of adjunctive inspiratory muscle training for patients with COPD. Thorax. 2018;73:942-50. https://doi.org/10.1136/ thoraxjnl-2017-211417.

32. Charususin N, Dacha S, Gosselink R, Decramer M, Von Leupoldt A, Reijnders $T$, et al. Respiratory muscle function and exercise limitation in patients with chronic obstructive pulmonary disease: a review. Expert Rev Respir Med. 2018;12(1):67-79. https://doi.org/10.1080/17476348.2018.1398084.

33. Gosselink R, De Vos J, van den Heuvel SP, Segers J, Decramer M, Kwakkel G. Impact of inspiratory muscle training in patients with COPD: what is the evidence? Eur Resp J. 2011;37(2):416-25. https://doi.org/10.1183/09031936.00031810.

34. Sawyer EH, Clanton TL. Improved pulmonary function and exercise tolerance with inspiratory muscle conditioning in children with cystic fibrosis. Chest. 104(5):1490-7. https://doi.org/10.1378/chest.104.5.1490.

35. Chatham K, lonescu A, Davies S, Baldwin J, Enright S, Shale D. Through range computer generated inspiratory muscle training in cystic fibrosis. Pediatr Pulmonol. 1997;340:S299.

36. ATdN S, GAdF F, Ramsook AH, Guenette JA, INDF L, Reid WD. Respiratory muscle endurance after training in athletes and non-athletes: a systematic review and meta-analysis. Phys Ther Sport. 2016;17:76-86. https://doi.org/1 0.1016/j.ptsp.2015.08.001.

37. Aswani N, Taylor C, McGaw J, Pickering M, Rigby A. Pubertal growth and development in cystic fibrosis: a retrospective review. Acta Paediatr. 2003; 92(9):1029-32. https://doi.org/10.1111/j.1651-2227.2003.tb02571.x.

38. Johannesson M, Gottlieb C, Hjelte L. Delayed puberty in girls with cystic fibrosis despite good clinical status. Pediatrics. 1997;99(1):29-34. https://doi. org/10.1542/peds.99.1.29.

39. McConnell AK, Weiner $P$, Romer LM. Inspiratory muscle training as a tool for the management of patients with COPD. Eur Resp J. 2004;24(3):510-1. https://doi.org/10.1183/09031936.04.00034904.

40. Marson FAL, Bertuzzo CS, Ribeiro JD. Personalized or precision medicine? The example of cystic fibrosis. Front Pharmacol. 2017:8(390). https://doi. org/10.3389/fphar.2017.00390.

41. Cholon DM, Gentzsch M. Recent progress in translational cystic fibrosis research using precision medicine strategies. J Cyst Fibros. 2018;17(2 Supplement):S52-S60. doi:https://doi.org/https://doi.org/10.1016/j.jcf.2017.09.005. 
42. Sheel AW, Boushel R, Dempsey JA. Competition for blood flow distribution between respiratory and locomotor muscles: implications for muscle fatigue. J Appl Physiol. 2018;125(3):820-31. https://doi.org/10.1152/ japplphysiol.00189.2018.

43. World Health Organization, 2001. International Classification of Functioning, Disability, and Health (ICF), Geneva

44. Mickleborough T, Stager J, Chatham K, Lindley M, Ionescu A. Pulmonary adaptations to swim and inspiratory muscle training. Eur J Appl Physiol. 2008;103(6):635-46. https://doi.org/10.1007/s00421-008-0759-x.

45. Shei R-J, Lindley MR, Chatham K, Mickleborough TD. Effect of flow-resistive inspiratory loading on pulmonary and respiratory muscle function in subelite swimmers. J Sports Med Phys Fitness. 2016;56(4):392-8.

46. Lomax M, Kapus J, Brown Pl, Faghy M. Impact of weekly swimming training distance on the ergogenicity of inspiratory muscle training in well trained youth swimmers. J Strength Cond Res. 2019:33(8):2185-93.

47. Burd NA, West DWD, Staples AW, Atherton PJ, Baker JM, Moore DR, et al. Lowload high volume resistance exercise stimulates muscle protein synthesis more than high-load low volume resistance exercise in young men. PLoS One. 2010; 5(8):e12033. https:/doi.org/10.1371/journal.pone.0012033.

48. Schoenfeld BJ, Peterson MD, Ogborn D, Contreras B, Sonmez GT. Effects of low-vs. high-load resistance training on muscle strength and hypertrophy in well-trained men. J Strength Cond Res. 2015;29(10):2954-63. https://doi. org/10.1519/jsc.0000000000000958.

49. Schoenfeld BJ, Wilson JM, Lowery RP, Krieger JW. Muscular adaptations in low- versus high-load resistance training: a meta-analysis. Eur J Sport Sci. 2016;16(1):1-10. https://doi.org/10.1080/17461391.2014.989922.

50. Shei R-J, Mickleborough TD. Unresolved questions that need to be addressed in order to maximize the efficacy of inspiratory muscle training. Phys Ther Sport. 2019;35:97-98. doi:https://doi.org/https://doi.org/10.1016/j. ptsp.2018.11.009.

51. Gething AD, Passfield L, Davies B. The effects of different inspiratory muscle training intensities on exercising heart rate and perceived exertion. Eur J Appl Physiol. 2004;92(1-2):50-5. https://doi.org/10.1007/s00421-004-1044-2.

52. Cahalin $L P$, Arena R. Novel methods of inspiratory muscle training via the test of incremental respiratory endurance (TIRE). Exerc Sport Sci Rev. 2015; 43(2):84-92. https://doi.org/10.1249/jes.0000000000000042.

53. Chatham K, Baldwin J, Griffiths H, Summers L, Enright S. Inspiratory muscle training improves shuttle run performance in healthy subjects. Physiotherapy. 1999;85(12):676-683. doi:http://dx.doi.org/https://doi.org/10.1 016/S0031-9406(05)61231-X.

54. Shei R-J, Chapman RF, Gruber AH, Mickleborough TD. Inspiratory muscle training improves exercise capacity with thoracic load carriage. Physiol Rep. 2018;6(3):e13558. https://doi.org/10.14814/phy2.13558.

55. Hebestreit H, Arets HGM, Aurora P, Boas S, Cerny F, Hulzebos EHJ, et al. Statement on exercise testing in cystic fibrosis. Respiration. 2015;90(4):332-51.

56. Sawicki GS, Sellers DE, Robinson WM. High treatment burden in adults with cystic fibrosis: challenges to disease self-management. J Cyst Fibros. 2009; 8(2):91-96. doi:https://doi.org/https://doi.org/10.1016/j.jcf.2008.09.007.

\section{Publisher's Note}

Springer Nature remains neutral with regard to jurisdictional claims in published maps and institutional affiliations.

\section{Submit your manuscript to a SpringerOpen ${ }^{\circ}$ journal and benefit from:}

- Convenient online submission

- Rigorous peer review

- Open access: articles freely available online

- High visibility within the field

- Retaining the copyright to your article

Submit your next manuscript at $\boldsymbol{\nabla}$ springeropen.com 